\title{
Gastric Antral Vascular Ectasia (GAVE): An Update on Clinical Presentation, Pathophysiology and Treatment
}

\author{
Christian P. Selinger ${ }^{a} \quad$ Yeng S. Ang ${ }^{a, b}$ \\ a Department of Gastroenterology, Royal Albert Edward Infirmary, Wigan, and b University of Manchester, \\ Manchester, UK
}

\section{Key Words}

Gastric antral vascular ectasia - Watermelon stomach • Chronic Gl bleeding • Endoscopic therapy • Systematic review

\begin{abstract}
Gastric antral vascular ectasia (GAVE), though a rare disorder, causes up to $4 \%$ of non-variceal upper Gl bleeding. This paper gives an overview of studies examining clinical presentation and pathophysiology, and reviews the current evidence for invasive and non-invasive treatments. GAVE is often associated with systemic illnesses, such as cirrhosis of the liver, autoimmune connective tissue disorders, bone marrow transplantation and chronic renal failure. The pathophysiological changes leading to GAVE have not been fully explained and remain controversial. Patient presentation varies from chronic iron-deficiency anaemia to heavy acute gastrointestinal bleeding. It is important to differentiate GAVE from portal hypertensive gastropathy as GAVE does not respond to measures reducing portal pressures. Endoscopic ablation (Nd:YAG-laser or argon plasma coagulation) is the first-line treatment of choice. As evidence for pharmacological therapy with oestrogen (and/or progesterone), tranexamic acid or thalidomide stems from case reports only, these should be used if endoscopic measures have failed to stop chronic blood loss. Surgical antrectomy should
\end{abstract}

be reserved for unresponsive cases as it is associated with a high mortality. Ultimately, treatment of the underlying medical co-morbidities may lead to resolution of GAVE.

Copyright $\odot 2008$ S. Karger AG, Basel

\section{Introduction}

For this review we identified relevant papers via an electronic search of OVID Medline (1960-2007) using the search terms 'gastric antral vascular ectasia', 'vascular ectasia', 'GAVE' and 'watermelon stomach'. Using the reference lists in these papers we identified further relevant articles.

What is today known as gastric antral vascular ectasia (GAVE) was first described by Rider et al. [1] in a patient with severe chronic iron-defiency anaemia. Gastroscopy showed a grey smooth mucosa of the corpum. In contrast, the antrum was reported to be 'fiery red ... with marked hypertrophic mucosal changes', adherent old blood and scattered areas of profuse bleeding were also noted. $\mathrm{Mi}$ croscopy revealed a chronic inflammation and an oedematous submucosa with large, dilated veins. Rider et al. [1] described this condition as 'an erosive type of gastritis with marked veno-capillary ectasia'.

A more accurate definition was made by Jabbari et al. in 1984 [2]. They defined GAVE as 'longitudinal antral

\section{KARGER}

Fax +4161306 1234 E-Mail karger@karger.ch www.karger.com (c) 2008 S. Karger AG, Basel 0012-2823/08/0772-0131\$24.50/0

Accessible online at: www.karger.com/dig
Dr. Christian P. Selinger

55 Miry Lane, Westhoughton

Bolton BL5 2HW (UK)

Tel. +44 7793941 109, E-Mail christian.selinger@web.de 
folds ... converging on the pylorus, containing visible columns of tortuous red ectatic vessels'. Histological appearances were described as hyperplasia of the mucosa with capillary ectasia and thrombosis, fibromuscular hyperplasia of the lamina propria and abnormal vessels in the submucosa. In accordance with the endoscopic appearance, which resembled the stripes on a watermelon, they dubbed the condition 'watermelon stomach'.

Visible columns of red tortuous ectatic vessels along the longitudinal folds of the antrum are pathognomonic for GAVE (see figure 1) [3]. The ectatic vessels are typically limited to the antrum. Stotzer et al. [4], however, postulated a high incidence of extra-antral lesions after $7 \mathrm{sub}$ jects in a series of 17 patients with GAVE were found to have lesions in the cardia as well. GAVE of the antrum can easily be mistaken for antral gastritis [5]. Histological features of GAVE include vascular ectasia within the mucosa as well as fibrin thrombi, fibrohyalinosis and spindle cell proliferation (see figures 3-5) [6]. These features are pathognomonic for GAVE. A negative biopsy does not, however, exclude GAVE as the lesions are focal and therefore easily missed on biopsy [7].

\section{Epidemiology}

Although GAVE is considered a rare medical condition, it accounts for up to $4 \%$ of all non-variceal upper gastrointestinal bleedings [8]. Typical initial presentations range from occult bleeding causing transfusion-dependent chronic iron-defiency anaemia to severe acute uppergastrointestinal bleeding, and there is a single report of GAVE presenting with gastric outlet obstruction [9].

Most patients with GAVE suffer from chronic medical conditions which are thought to be causally related to it. Cirrhosis of the liver is found in 30\% of GAVE patients [10]. Data obtained from screening gastroscopies on patients undergoing liver transplantation suggest that 1 in 40 patients with endstage liver disease has GAVE [10].

In non-cirrhotic patients with GAVE autoimmune diseases are most common, with incidences of $62 \%$ for autoimmune connective tissue disorders, $31 \%$ for Raynaud's phenomenon and $20 \%$ for sclerodactily [11]. Other conditions described in GAVE patients include scleroderma, bone marrow transplantation, chronic renal failure, ischaemic heart disease, hypertension, valvular heart disease, familial Mediterranean fever and acute myeloid leukaemia [11-14].

Recently, 2 papers reported that cirrhosis is commonly linked with a diffuse appearance of GAVE on endos- copy, whereas non-cirrhotic patients are more likely to have a typical stripy watermelon appearance $[15,16]$. Whereas the majority of non-cirrhotic GAVE patients are females $(71 \%)$, with a mean age of 73 years, cirrhotic GAVE patients tend to be younger (mean age 65 years) and male (75\%) $[11,17]$. This is most likely explained by the age and sex distribution of patients suffering from either connective tissue disorder or liver cirrhosis.

\section{Differentiation from Portal Hypertensive Gastropathy}

A clinical dilemma can arise in patients with known liver cirrhosis or portal hypertension of other causes in whom an upper gastrointestinal endoscopy suggests an abnormal vascular pattern in the gastric mucosa. Payen et al. [6] established in 1995 that portal hypertensive gastropathy (PHG) and GAVE are distinct entities that require different treatments. It is, therefore, vitally important to distinguish between them.

Whereas GAVE is most commonly limited to the antrum, PHG predominantly causes changes of the mucosa in the fundus and corpus [7]. GAVE patients have more severe liver disease, greater blood loss, lower serum gastrin levels and a higher incidence of previous sclerotherapy [6]. Biopsy has proved to be the best way of distinguishing between GAVE and PHG. Microvascular thrombi, vascular ectasia, spindle cell proliferation and fibrohyalinosis in antral biopsies have all been shown to be significantly more associated with GAVE than PHG. Combining spindle-cell proliferation and fibrohyalinosis as diagnostic factors for GAVE versus PHG results in an accuracy of $85 \%$ [6].

\section{Pathophysiology}

The understanding of the pathophysiological changes leading to GAVE remains poor. Most theories are either based on case reports of single patients or small studies with 15 or fewer cases.

The main focus of research into the causes of GAVE is limited to the subgroup of patients suffering from liver cirrhosis and portal hypertension (30\% of patients). It has become clear, however, that portal hypertension does not play an important role in the development of GAVE. This is supported by findings that there is no significant correlation between the degree of vascular ectasia (mean mucosal capillary cross-sectional area) and the degree of 


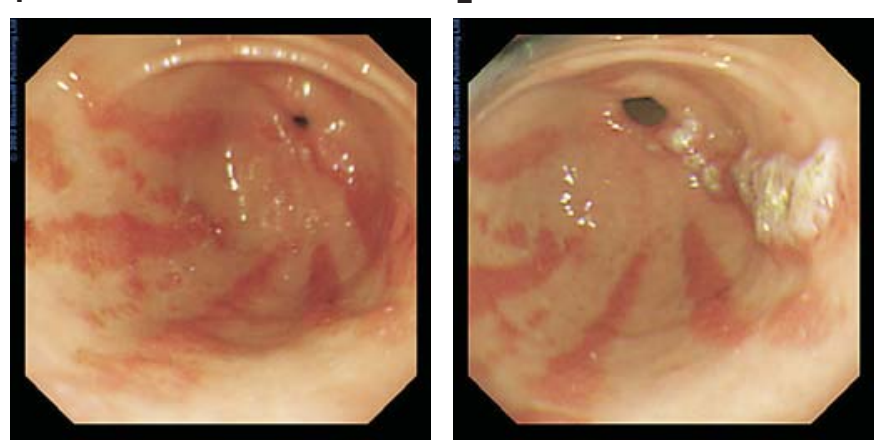

Fig. 1. Ectatic vessels along the longitudinal folds of the antrum. Image from Schiller et al. [56], reproduced with kind permission from Blackwell Publishing Ltd.

Fig. 2. GAVE after argon plasma coagulation on one fold (on the right of image). Image from Schiller et al. [56], reproduced with kind permission from Blackwell Publishing Ltd.

portal hypertension [18]. It is also evidenced by the lack of response to reduction in portal pressures.

Despite the fact that a causal relationship between GAVE and cirrhosis seems likely, to this day no convincing evidence of this has been found. A report of 3 patients showing a complete resolution of GAVE following liver transplantation suggests, again, a causal link [10]. Further support for this theory is provided by the fact that GAVE patients tend to have higher degrees of liver dysfunction than patients with portal hypertensive gastropathy [6].

Some authors have linked GAVE with achlorhydria, raised levels of gastrin and low levels of pepsinogen [11, 18]. This seems to be independent from the presence of cirrhosis as Quintero et al. [18] only report on cirrhotic patients and Gostout et al. [11] report on a mixed patient group with a predominance of autoimmune diseases. Quintero et al. [18] found gastrin levels to be significantly raised in 8 of 11 patients with GAVE and cirrhosis when compared with control patients (0 of 13) and with cirrhosis patients without gastric mucosal changes ( 2 of 18). In accordance with this, pepsinogen levels were significantly higher in the GAVE group than in the 2 other groups.

In contrast to those findings stands a study of $14 \mathrm{pa}-$ tients with GAVE and cirrhosis who were found to have low gastrin levels [6]. It was, however, pointed out by the authors that there is a discrepancy in the literature about the normal value of gastrin levels in cirrhotic patients. The peptide-hormone gastrin is known to increase gastric vasodilation [19]. Whether this is at least partially responsible for the development of GAVE remains un-

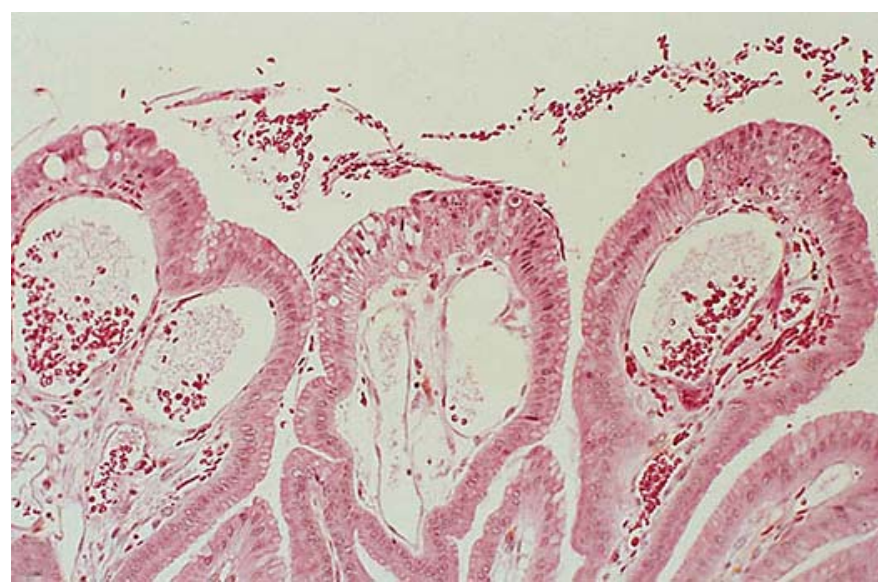

Fig. 3. Histology of ectatic capillaries. Image from Tobin et al. [57], reproduced with permission from Elsevier.

clear. Prostaglandin $\mathrm{E}_{2}$ is another hormone with vasodilating properties; in a single study it was found to be significantly raised in cirrhosis patients with GAVE compared to those without [20].

A histological study by Lowes and Rode [21] on a single patient with GAVE found extra-epithelial and intra-epithelial proliferations of neuroendocrine cells in close proximity to ectatic blood vessels. A majority of these showed immunoreactivity for 5-hydroxytryptamine and vasoactive inhibitory peptide. The authors go on to speculate that locally high concentrations of the neurotransmitters lead to the development of GAVE.

Antral motility studies by Charneua et al. [22] showed an abnormal pattern in patients with GAVE and cirrhosis. Using ultrasound they found antral area half-time to be significantly increased when comparing these patients to healthy controls. This finding gives support to the idea of mechanical stress playing an important role in the pathogenesis of GAVE.

The theory of mechanical stress was first postulated by Quintero et al. [18]. Peristaltic waves are believed to cause a partial prolapse of loosely attached distal gastric mucosa through the pyloric ring. This draws mucosa into accentuated longitudinal folds and induces fibromuscular hyperplasia of the antrum and formation of ectatic vessels as a secondary reaction. Lowes and Rode [21] support the theory of mechanical stress as they found no other explanation for the typical pattern of distribution of GAVE lesions.

Authors reporting on GAVE following bone-marrow transplant and GAVE in connection with autoimmune 
4

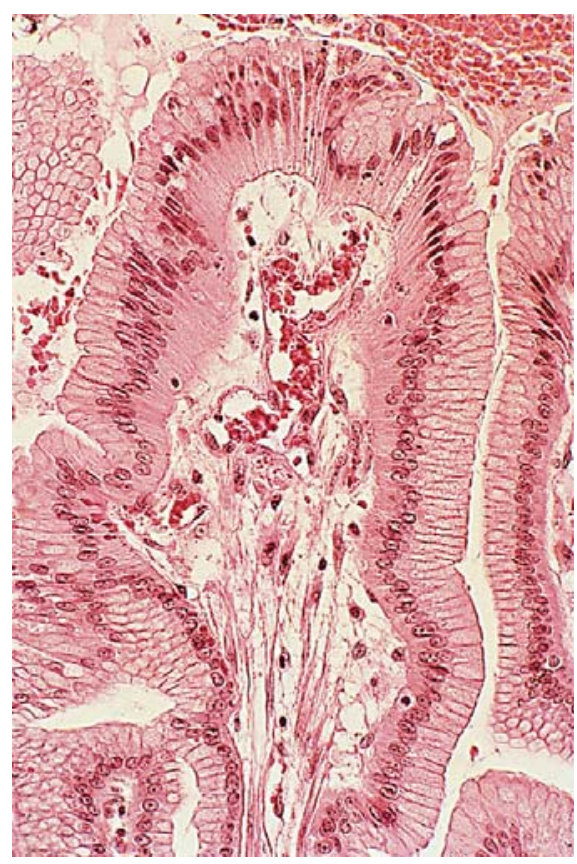

5

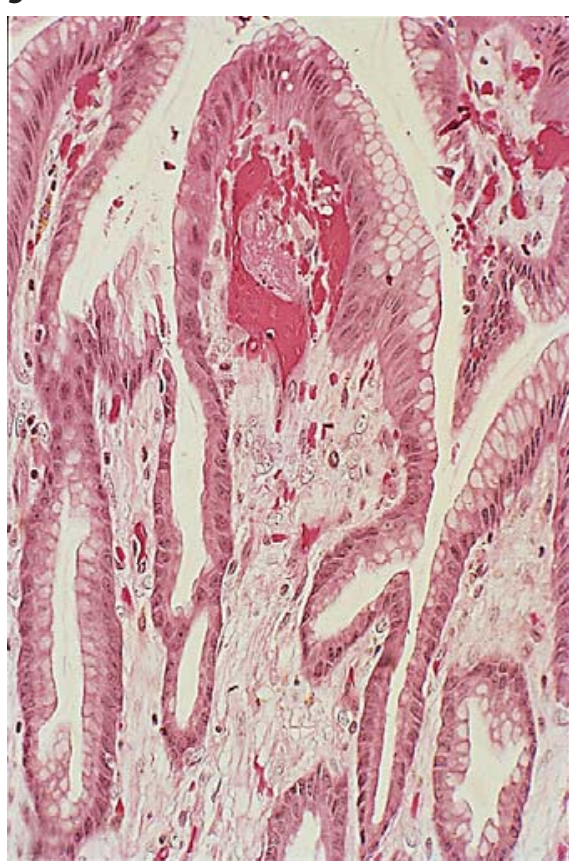

Fig. 4. Vascular ectasia and slender, hyperplastic fibromuscular cells in lamina propria. Image from Tobin et al. [57], reproduced with permission from Elsevier.

Fig. 5. Capillary thrombosis. Image from Tobin et al. [57], reproduced with permission from Elsevier.

Table 1. Results of Nd:YAG laser treatment

\begin{tabular}{|c|c|c|c|c|}
\hline Study & $\begin{array}{l}\mathrm{Pa}- \\
\text { tients }\end{array}$ & Follow-up & $\begin{array}{l}\text { No further } \\
\text { transfusions } \\
\text { required }\end{array}$ & Comment \\
\hline Goustout et al. [11] & 45 & Median 2 years (2-72 months) & $86 \%$ & \\
\hline Liberski et al. [31] & 10 & Mean 4.4 years (2-8 years) & $100 \%$ & 5 patients dying of unrelated causes were excluded \\
\hline Bjorkman and Buchi [47] & 4 & Mean 2.9 years & $100 \%$ & 1 patient required retreatment \\
\hline
\end{tabular}

disease have not found causal links between the underlying condition and the development of GAVE $[11,12]$. The development of an animal model may be the way forward to identify the aetiology and explain the pathophysiology of GAVE.

\section{Therapy}

\section{Symptomatic Therapy and Non-Invasive Medical}

Therapy

Purely symptomatic therapy aims for a correction of the chronic or acute blood loss from GAVE. This includes fluid resuscitation and blood transfusions for acute bleeding episodes as well as iron supplementation and, if required, repeated blood transfusions for chronic occult bleeding.
Medical therapy aimed at reducing portal hypertension has not been successful in trying to reduce the incidence of bleeding episodes and transfusion requirements. A study reporting improvement in bleeding from gastric mucosal lesions by using beta-blockers is of little value as it did not distinguish between GAVE and PHG, which is well known to respond to a reduction in portal pressures by propranolol $[23,24]$. In a group of 8 patients with GAVE and cirrhosis, neither beta-blockade (nadolol) nor shunting of the portal venous system with a transjugular intrahepatic shunt (TIPS) led to control of chronic blood loss [17].

Other medical treatment approaches aim at stopping bleeding without trying to reduce antral lesions or portal pressures. Initially corticosteroids were used to treat GAVE and case reports showed that 4 out of 11 patients responded to this measure [2, 25-31, 34, 36-38]. Typical 
steroid side effects, like steroid-induced diabetes mellitus and/or cushing-like illness, limit its use. Several case reports describe successful treatment with oestrogen and progesterone [32-35].

Two case reports indicate that tranexamic acid can be effective in reducing bleeding episodes and transfusion requirements. Blood loss was reduced in a GAVE patient with alcohol-induced liver cirrhosis [36]. Another cirrhotic patient, who previously required 130 transfusion units of packed cells and did not respond to a TIPS, was commenced on tranexamic acid. Despite endoscopic evidence of persistence of GAVE lesions, no further blood transfusions were required during a 30-month follow-up [37]. It is, however, important to stress that ischaemic events and pulmonary emboli have been reported as adverse events connected with the use of tranexamic acid [38].

Thalidomide was found to be effective in a single case [39]. A patient unresponsive to endoscopic therapy became transfusion independent within 3 months of commencement of thalidomide and remained so for a further 9 months of follow-up. Others agents, such as alpha-interferon, calcintonin and cyprohepatdine, have been used successfully in single cases [27, 40, 41].

Treatment of the underlying disease can lead to resolution of GAVE as reported in liver transplantation or systemic sclerosis $[10,42]$. However, there is also a report of a systemic sclerosis patient in remission who experienced recurrent relapses of GAVE [43].

\section{Endoscopic Therapy}

Sclerotherapy, heater probe and laser photocoagulation can be applied via a flexible endoscope to treat vascular mucosal lesions of the gastrointestinal tract (see figure 2). During the 1980s the first reports of their usefulness in treating GAVE were published. While there is only limited experience with sclerotherapy [44] and heater probe [45], laser photocoagulation has established itself as the endoscopic therapy of choice.

Several studies of laser photocoagulation followed an early case report from Frager et al. [46]. Gostout et al. [11] showed endoscopic and haematological (elimination of transfusion need) improvements in 12 of 13 previously transfusion-dependent GAVE patients. Their patients were treated with a neodymium:yttrium-aluminiumgarnetlaser (Nd:YAG-laser) and followed-up for 6 months . Larger studies with longer follow-up periods confirmed these early positive findings (see table 1).

Argon plasma coagulation for GAVE has been shown to be effective as well. However, 3 patients treated successfully with an argon laser required repeated treat- ments [47]. In a series of 26 GAVE patients treated with argon plasma coagulation, transfusion requirements were abolished in 77\% over a 16-month median follow-up period [48].

It has, however, been reported that several treatment sessions might be required to abolish transfusion dependence [49]. Argon plasma coagulation is equally effective for treatment of diffuse GAVE and stripy (watermelon appearance) GAVE $[15,16]$. Improvement of hepatic encephalopathy in cirrhotic patients has been shown to be an additional benefit of argon plasma coagulation of GAVE lesions [50]. To this day, only 1 serious adverse event to endoscopic therapy has been reported: a 74-yearold man developed gastric outlet obstruction 8 months after he had undergone 7 sessions of argon plasma coagulation for GAVE [51]. Successful treatment of GAVE by endoscopic band ligation has been reported in a single case [52].

\section{Surgical Therapy}

Before the establishment of endoscopic therapies, antrectomy was the only long-term solution for GAVE patients and it remains a curative treatment for GAVE. However, several case reports indicate that antrectomy is associated with a high rate of morbidity and mortality when attempted in a setting of liver cirrhosis with portal hypertension $[29,53]$. A 30 -day mortality of $50 \%$ was reported in 4 patients requiring antrectomy to control bleeding from GAVE lesions [17].

Patients suffering from GAVE and portal hypertension were thought to benefit from reduction in portal pressures. Medical attempts using beta-blockers failed to reduce bleeding episodes and transfusion requirements (see Symptomatic Therapy and Non-Invasive Medical Therapy). Procedures aimed at reducing portal pressures include surgical construction of portosystemic shunts (SPSS) and radiological placement of TIPS. Initial case reports showed disappointing results [30, 37]. A small series of 8 (7 TIPS, 1 SPSS) showed a significant reduction in portal pressures in 7 cases. In only 1 case, however, was an abolishment of transfusion requirements achieved [17]. TIPS in 14 patients with GAVE and portal hypertension due to liver cirrhosis failed to achieve resolution of gastric lesions and reduction in transfusion requirements [54].

Despite the clear evidence that a reduction in portal hypertension does not affecting bleeding from GAVE, there is a suggestion that orthoptic liver transplantation (OLT) can improve GAVE [10]. Three patients showed a complete endoscopic resolution of GAVE after OLT. None of these experienced any gastrointestinal bleeding. 


\section{Summary}

GAVE, also named watermelon stomach, is a rare entity, but is found in about $4 \%$ of all non-variceal upper gastrointestinal bleeding [8]. The real incidence remains unknown as only symptomatic patients will undergo gastroscopy and then be diagnosed. Furthermore, the tendency to bleed is probably overestimated as most studies reporting on GAVE are subject to selection bias. The only study capable of estimating prevalence suggests the presence of GAVE in 1 in 40 end-stage liver disease patients [10].

The aetiology of GAVE remains poorly understood. Most attempts to explain the development of GAVE are based on single case reports or small studies (some without control groups) of 15 or fewer patients. GAVE is usually found in patients suffering from severe co-morbidities like liver cirrhosis, autoimmune connective tissue diseases, chronic renal failure and bone marrow transplantation. Attempts should be made to identify any underlying co-morbidities, as treatment of these can lead to the resolution of GAVE. Despite the fact that only $30 \%$ of GAVE patients suffer from liver cirrhosis most studies have looked into this subgroup. A causal link between cirrhosis and GAVE seems likely as these patients have higher degrees of liver failure [5] and liver transplantation can lead to resolution of GAVE [10]. Portal hypertension, however, is unlikely to be important in the pathogenesis as there is a clear lack of response to measures reducing portal pressures (beta-blockade, TIPS). No model of how liver cirrhosis causes GAVE has been published to this day.

There have been several suggestions that hormonal abnormalities lead to the development of GAVE. The role of gastrin and pepsinogen levels is unclear as studies have shown conflicting results $[6,18]$. Only 1 study found raised Prostaglandin $\mathrm{E}_{2}$ levels [20]. Based on a single case, proliferations of neuroendocrine cells producing 5-hydroxytryptamine and vasoactive inhibitory peptide have been postulated as a causal factor [21].

Two studies suggest a role for abnormal antral motility and physical stress on the mucosa $[18,21]$. The evidence for all 4 of the above theories remains patchy and unconvincing. Most patients suffering from GAVE present with iron-defiency anaemia, but few will have signs of acute upper gastrointestinal bleeding. The diagnosis will be made on endoscopy. If there is uncertainty whether mucosal abnormalities are due to PHG or GAVE, biopsies will help to distinguish between the 2 conditions [6].

Making the right diagnosis in these cases is vitally important as PHG, in contrast to GAVE, will respond well to a reduction in portal pressures [17]. Treatment options for GAVE include endoscopic ablation (Nd:YAG-laser or argon plasma coagulation), surgical antrectomy or pharmacological therapy with oestrogen (and/or progesterone), tranexamic acid or thalidomide.

The evidence for pharmacological therapies arises from uncontrolled case reports only and can therefore be classified as level 4 on the Oxford Centre for EvidenceBased Medicine Levels of Evidence scale [55]. Surgical antrectomy is a curative approach, but may have a high morbidity and mortality in the setting of GAVE [17]. The evidence is, again, level 4.

Endoscopic therapies were originally based on $\mathrm{Nd}$ : YAG-laser, but there is a shift towards argon plasma coagulation in the more recent literature. Both techniques have been shown to effectively control bleeding from GAVE $[11,48]$. The key studies together report on over 100 patients, but are all open label and have no control arms (evidence level 4).

As all treatment studies lack control groups, recommendations arising from them can only be grade $\mathrm{C}(\mathrm{Ox}-$ ford Centre for Evidence-Based Medicine).

\section{Acknowledgements}

The authors would like to thank Elsevier and Blackwell Publishing for the right to use the illustrations. This clinical review was initially conducted by C.P.S. as part of a masters degree at the University of Salford, Salford, UK.

References veno-capillary ectasia as a source of massive gastric hemorrhage. Gastroenterol 1953;24: $118-123$.

2 Jabbari M, Cherry R, Lough JO, et al: Gastric antral vascular ectasia: the watermelon stomach. Gastroenterol 1984;87:1165-1170.

-3 Novitsky YW, Kercher KW, Czerniach DR, et al: Watermelon stomach: pathophysiology, diagnosis and management. J Gastrointest Surg 2003;7:652-661.

-4 Stotzer PO, Willeri R, Kilander AF: Watermelon stomach: not only an antral disease. Gastrointest Endosc 2002;55:897-900.

5 Gardiner GW, Murray D, Prokipachuk EJ: Watermelon stomach, or antral gastritis. J Clin Pathol 1985;85:1317-1318.

-6 Payen JL, Cales P, Voigt JJ, et al: Severe portal hypertensive gastropathy and antral vascular ectasia are distinct entities in patients with cirrhosis. Gastroenterol 1995;108:138144

7 Burak KW, Beck PL: Portal hypertensive gastropathy and gastric antral vascular ectasia (GAVE) syndrome. Gut 2001;49:866-872. 
8 Dulai GS, Jensen DM, Kovacs TO, et al: Endoscopic treatment outcomes in watermelon stomach patients with and without portal hypertension. Endoscopy 2004;36:68-72.

-9 Tuveri M, Borsezio V, Gabbas A, et al: Gastric antral vascular ectasia - an unusual cause of gastric outlet obstruction: report of a case. Surgery Today 2007;37:503-505.

10 Ward EM, Raimondo M, Rosser BG, et al: Prevalence and natural history of gastric antral vascular ectasia (GAVE) in patients undergoing orthoptic liver transplantation. J Clin Gastroenterol 2004;38:898-900.

-11 Gostout CJ, Viggiano TR, Ahlquist DA, et al: The clinical and endoscopic spectrum of the watermelon stomach. J Clin Gastroenterol $1992 ; 15: 256-263$.

- 12 Tobin RW, Hackman RC, Kimmey MB, et al: Bleeding from gastric antral vascular ectasia in marrow transplant patients. Gastrointest Endosc 1996;44:223-229.

-13 Sebastian S, O’Morain CA, Buckley MJ: Review article: current therapeutic options for gastric antral vascular ectasia. Aliment Pharmacol Ther 2003;18:157-165.

14 Takahashi T, Takuya M, Oki M, et al: Severe hemorrhage from gastric antral vascular ectasia developed in a patient with AML. Int J Hematol 2006;83:467-468.

15 Ito M, Uchida Y, Kamano S, et al: Clinical comparison between two subsets of gastric antral vascular ectasia. Gastrointest Endoscopy 2001;53:764-770.

16 Chaves DM, Sakai P, Oliveira CV, et al: Watermelon stomach: clinical aspects and treatment with argon plasma coagulation. Arq Gastroenterol 2006;43:191-195.

17 Spahr L, Villeneuve JP, Dufresne MP, et al: Gastric antral vascular ectasia in cirrhotic patients: absence of relation with portal hypertension. Gut 1999;44:739-742.

$\checkmark 18$ Quintero E, Pique JM, Bombi JA, et al: Gastric mucosal vascular ectasias causing bleeding in cirrhosis. A distinct entity associated with hypergastrinemia and low serum levels of pepsinogen I. Gastroenterol 1987;93:1054-1061.

19 Guth P, Smith E: The effect of gastrointestinal hormones on the gastric microcirculation. Gastroenterology 1976;17:700-708.

-20 Samperal E, Perez-Ayuso RM, Poca E, et al: Increased gastric PGE2 biosynthesis in cirrhotic patients with gastric vascular ectasia. Am J Gastroenterol 1990;85:138-144.

-21 Lowes JR, Rode J: Neuroendocrine cell proliferations in gastric antral vascular ectasia. Gastroenterology 1989;97:207-212.

-22 Charneua J, Petit R, Cales P, et al: Antral motility in patients with cirrhosis with or without gastric antral vascular ectasia. Gut 1995; 37:488-492.

23 Hosking SW, Kennedy HJ, Seddon I, et al: The role of propranolol in congestive gastropathy of portal hypertension. Hepatology 1987;7:437-441.

24 Pérez-Ayuso RM, Piqué JM, Bosch J, et al: Propranolol in prevention of recurrent bleeding from severe portal hypertensive gastropathy in cirrhosis. Lancet 1991;337:14311434.
25 Calam J, Walker RJ: Antral vascular lesion, achlorhydria and chronic gastrointestinal blood loss: response to steroids. Digest Dis Sci 1980;25:236-239.

26 Bowmick BK: Watermelon stomach treated with oral corticosteroid. J R Soc Med 1993; 86:52.

27 Kishi K, Kinoshita Y, Kitajima N, et al: Two cases of gastric antral vascular ectasia - response to medical treatment. Gastroenterol Jpn 1991;26:757-762.

28 Rawlinson D, Bare CD, Lin BP: Antral vascular ectasia - the watermelon stomach. Med J Austr 1986;144:709-711.

29 Kruger R, Ryan ME, Dickson KB, et al: Diffuse vascular ectasia of the gastric antrum. Am J Gastroenterol 1987;82:421-426.

30 Cales P, Voigt JJ, Payen JL, et al: Diffuse vascular ectasia of the antrum, duodenum, and jejunum in a patient with nodular regenerative hyperplasia. Lack of response to portosystemic shunt or gastrectomy. Gut 1993;34 558-561.

31 Liberski SM, McGarrity TJ, Hartle RJ, et al: The watermelon stomach: long-term outcome in patients treated with Nd:YAG laser therapy. Gastrointest Endosc 1994;40:584-587.

32 Schoonbroodt D, Horsmans Y, Hoang P, et al: Vascular gastric anomalies, CREST syndrome and primary biliary cirrhosis: efficacy of ethinyl estradiol-noresthisterone combination (in French). Gastroenterol Clin Biol 1994;18:649-651.

33 Manning RJ: Estrogen/progesterone treatment of diffuse antral vascular ectasia. Am J Gastroenterol 1995;90:154-156.

34 Moss SF, Ghosh P, Thomas DM, et al: Gastric antral vascular ectasia: maintenance oestrogen-progesterone. Gut 1992;33:715-717.

35 Tran A, Villeneuve JP, Bilodeau M, et al: Treatment of chronic bleeding from gastric antral vascular ectasia (GAVE) with estrogen-progesterone in cirrhotic patients: an open pilot study. Am J Gastroenterol 1999; 94:2909-2911.

36 Park RH, Danesh BJ, Upadhyay R, et al: Gastric antral vascular ectasia (watermelon stomach) - therapeutic options. Postgrad Med J 1990;66:720-723.

37 McCormick PA, Ooi H, Crosbie O: Tranexamic acid for severe bleeding gastric antral vascular ectasia in cirrhosis. Gut 1998;42:750752.

38 Woo KS, Tse LK, Woo JL, et al: Massive pulmonary thromboembolism after tranexamic acid antifibrinolytic therapy. Br J Clin Pract 1989;43:465-466.

39 Dunne KA, Hill J, Dixon JF: Treatment of chronic transfusion-dependent gastric antral vascular ectasia (watermelon stomach) with thalidomide. Eur J Gastroenterol Hepatol 2006; 18:455-456.

40 Disdier P, Schleinitz N, Perreard M, et al: Dramatic improvement of watermelon stomach with alpha-interferon. Am J Gastroenterol 1995;90:1009-1010.

41 Pina Cabral JE, Pontes JM, Toste M, et al: Watermelon stomach: treatment with a serotonin antagonist. Am J Gastroenterol 1991; 86:927-928.
42 Lorenzi AR, Johnson AH, Davies A, et al: Gastric antral vascular ectasia in systemic sclerosis: complete resolution with methylprednisolone and cyclophosphamide. Ann Rheum Dis 2001;60:796-798.

43 Shibukawa G, Irisawa A, Sakamoto N, et al: Gastric antral vascular ectasia (GAVE) associated with systemic sclerosis: relapse after endoscopic treatment by argon plasma coagulation. Intern Med 2007;46:279-283.

44 Coli-Jones DG: Upper Gastrointestinal Lesions. London, Chapman \& Hall Medical, 1984.

45 Petrini JL, Johnston JH: Heater probe therapy for vascular ectasia of the antrum. Gastrointest Endosc 1986;32:174-175.

46 Frager JD, Brandt LJ, Frank MS, et al: Treatment of a patient with watermelon stomach using transendoscopic laser photocoagulation. Gastrointest Endoscopy 1988;34:134-137.

47 Bjorkman DJ, Buchi KN: Endoscopic laser therapy of the watermelon stomach. Lasers Surg Med 1992;12:478-481.

48 Kwan V, Bourke MJ, Williams SJ, et al: Argon plasma coagulation in the management of symptomatic gastrointestinal vascular lesions: experience in 100 consecutive patients with long-term follow-up. Am J Gastroenterol 2006;101:58-63.

49 Yusoff I, Brennan F, Ormonde D, et al: Argon plasma coagulation for treatment of watermelon stomach. Endoscopy 2002;34:407410.

50 Zushi S, Imai Y, Fukuda K, et al: Endoscopic coagulation therapy is useful for improving encephalopathy in cirrhotic patients with gastric antral vascular ectasia. Digest Endoscopy $2005 ; 17: 32-35$.

\$1 Farooq FT, Wong RC, Yang P, et al: Gastric outlet obstruction as a complication of argon plasma coagulation for watermelon stomach. Gastrointest Endosc 2007;65:1090-1092.

52 Sinha SK, Udawat HP, Varma S, et al: Watermelon stomach treated with endoscopic band ligation. Gastrointest Endosc 2006;64:10281031.

53 Jouanolle H, Bretagne JF, Ramee MP, et al: Antral vascular ectasia and scleroderma. Endoscopic, radiologic and anatomopathologic aspects of an uncommon association (in French). Gastroenterol Clin Biol 1989;13: 217-221.

54 Kamath PS, Lacerda M, Ahlquist DA, et al: Gastric mucosal responses to intrahepatic portosystemic shunting in patients with cirrhosis. Gastroenterology 2000;118:905-911.

55 Phillips B, Ball C, Sackett D, et al: Levels of Evidence. Oxford, Oxford Centre for Evidence-Based Medicine, 2001. www. cebm.net/index.aspx?o=1025 (last accessed 22.01.2008).

56 Schiller K, Warren B, Cockel R: Slide Atlas of Gastrointestinal Endoscopy and Related $\mathrm{Pa}$ thology. Oxford, Blackwell Publishing, 2003.

57 Tobin RW, Hackman RC, Kimmey MB, et al: Bleeding from gastric antral vascular ectasia in marrow transplant patients. Gastrointest Endosc 1996;44:223-229. 